Asian-Australasian Journal of

Food Safety and Security

ISSN 2523-1073 (Print) 2523-2983(Online)

www.ebupress.com/journal/aajfss

\title{
Article \\ Antibiotic resistance and residue in chicken, cattle, buffalo and goat meats in different southern districts of Bangladesh
}

Bidyut Matubber ${ }^{1,2}$, Farzana Islam Rume ${ }^{1 *}$, Mohammad Enamul Hoque Kayesh ${ }^{1}$, Mohammad Mahfuzur Rahman ${ }^{1}$, Mohammad Rohul Amin ${ }^{3}$, Md. Ali Asgar ${ }^{3}$ and A. K. M. Mostafa Anower ${ }^{1 *}$

${ }^{1}$ Department of Microbiology and Public Health, Patuakhali Science and Technology University, Babugonj, Barishal-8210, Bangladesh

${ }^{2}$ Department of Microbiology and Public Health, Khulna Agricultural University, Khulna-9100, Bangladesh

${ }^{3}$ Department of Physiology and Pharmacology, Patuakhali Science and Technology University, Babugonj, Barishal-8210, Bangladesh

*Corresponding author: Farzana Islam Rume and A. K. M. Mostafa Anower, Department of Microbiology and Public Health, Patuakhali Science and Technology University, Babugonj, Barishal-8210, Bangladesh. Phone: +8801711226056 (Farzana Islam Rume), +8801711069468 (A. K. M. Mostafa Anower); E-mail: farzanarume@pstu.ac.bd (Farzana Islam Rume), anower@pstu.ac.bd (A. K. M. Mostafa Anower)

Received: 31 March 2021/Accepted: 22 May 2021/ Published: 31 May 2021

\begin{abstract}
The presence of antibiotic residue in chicken and animal meats is a serious threat to human health due to its harmful effects. This study aimed at identifying the antibiotic resistance patterns of the isolates as well as antibiotic residues in chicken, cattle, buffalo and goat meats in different southern districts of Bangladesh. A total of 205 meat samples, including 70 chicken meat, 60 cattle meat, 50 buffalo meat and 25 goat meat were aseptically collected and analysed for the detection of antibiotic residues by thin layer chromatography and the isolates obtained from these samples were subjected to antibiogram study against 16 commonly used antibiotics. The isolates found in this study were Staphylococcus spp., Streptococcus spp., Escherichia coli, and Salmonella spp. and their prevalence were $37.5 \%$ (77/205), 22.1\% (48/205), 29.7\% (61/205), 8.7\% (19/205), respectively. The isolates showed different degrees of sensitivity to the antibiotics used in the study. The most resistant phenotype was against cefradine, amoxicillin, penicillin, oxytetracycline, erythromycin, and enrofloxacin. $18.5 \%$ (38/205) meat samples were found to be positive for antibiotic residues and the highest prevalence was observed in chicken meat compared to other meat types. Overall, the findings of the study suggest that it is important to take controlling measures for the emergence of antibiotic resistance and also for ensuring healthy meats for human consumption.
\end{abstract}

Keywords: antibiotic; resistance; residue; meat; TLC

\section{Introduction}

In veterinary medicine antibiotics are commonly used, therefore, foods derived from animals may contain antibiotic residues, which can adversely affect the human health (Chanda et al., 2014). Also, administration of antibiotics to farm animals may impose certain hazards to human and animal health, including increased resistance of bacteria to antibiotics as well as allergic reaction (Walton 1988; Mathew et al., 2001). However, worldwide farmers use antibiotics for therapeutic and prophylactic purposes, and also as growth promoter (Jinap et al., 2010; Wadoum et al., 2016). Therefore, food-producing animals remain as an important source of antimicrobial-resistant zoonotic bacteria (Michael et al., 2017). In addition, indiscriminate use of antibiotics results residues in meat, milk, cheese, butter and other livestock products (Lee et al., 2001). Antibiotics belonging to tetracycline, aminoglycoside, sulphonamide and potentiated sulphonamide, macrolide and lincosamide groups are commonly used as growth promoter at sub-therapeutic doses in poultry (Casewell et al., 
2003). Sulphonamides can also be used as additives in animal food, as prolonged ingestion of sulphonamides influence the growth-promoting effect (Long et al., 1990). Tetracycline, a broad-spectrum antibiotic is used to treat infections as well as growth promoter in animals (Doyle et al., 2006).

It is assumed that antibiotic residues in animal derived foods might be a potential source of human health hazards, and antibiotics resistance may significantly affect the health condition of both humans and animals. However, the antibiotic resistance of the isolates from different meat samples and presence of antibiotic residues in different meats are not well documented in Bangladesh. Therefore, in this study, we characterized the antibiotic resistance of the isolates obtained from different meat samples, including chicken meat, cattle meat, buffalo meat, and goat meat collected from different southern districts of Bangladesh. Also, we investigated the prevalence of antibiotic residues in these meat samples. The findings of the study should provide a documentation of the antibiotic resistance and antibiotic residues in meats of Bangladesh.

\section{Materials and Methods \\ 2.1. Collection of samples}

A total of 205 meat samples, including 70 poultry meat, 60 cattle meat, 50 buffalo meat, and 25 goat meat were aseptically collected from three different southern districts of Bangladesh, including Barishal, Pirojpur and Bhola.

\subsection{Transportation of samples}

Samples were collected in sterile containers and transported to the laboratories maintaining the standard procedures. Each sample was divided into two aliquots, one aliquot was shipped to the laboratory of the Department of Microbiology and Public Health, Patuakhali Science and Technology University for isolation and characterization of isolates and another aliquot was shipped to the laboratory of the Department of Microbiology and Veterinary Public Health, Chittagong Veterinary and Animal Sciences University, Chittagong for antibiotic residue detection by thin layer chromatography (TLC).

\subsection{Isolation and identification of bacterial agents}

Isolation of bacterial agents from the meat samples were performed by culturing the samples in different plates containing culture media, including eosin methylene blue (EMB) agar, MacConkey agar, xylose lysine deoxycholate (XLD) agar, salmonella and shigella agar (SS agar), mannitol salt agar (MS agar), nutrient agar (NA), blood agar (BA), strep agar and mueller-hinton agar. Plates were incubated at $37^{\circ} \mathrm{C}$ for $24-48$ hours under aerobic condition. From the pure culture bacterial agents were identified by studying colony characteristics, Gram staining reaction, hemolysis pattern and biochemical test as described by Merchant and Packer (1967) and Cheesbrough (1984).

\subsection{Antibiogram study}

To know the antibiotic sensitivity pattern of the isolates against different commonly used antibiotics, antibiotic sensitivity test was performed by Disc Diffusion test as described previously (Bauer et al.,1966). This method is suitable for the determination of an in vitro efficacy of antibiotics by calculating the zone of inhibition diameter, which are caused by diffusion of the agent into the medium surrounding the disc. Sixteen commercially available antibacterial agents (Himedia Laboratories, India) were selected for the purpose. Antibiotics used in this study and their concentration per disc and diameter of zone of inhibition used for interpreting the sensitivity of the isolates are shown in Table 1.

\subsection{Detection of antibiotic residues in meat}

Thin layer chromatography (TLC) was performed to detect the presence of drug residues in meat samples, according to the method described previously (Poppelka et al., 2005). Briefly, meat samples were blended for 3 minutes and taken into Petri dishes. Using spatula .04" of blended meat sample was taken into beaker. Then, 10 $\mathrm{ml}$ of phosphate buffered solution was added and mixed well. Next, $2 \mathrm{ml}$ of trichloroacetic was added to the solution and centrifuged at $7000 \mathrm{rpm}$ for 15 minutes. After centrifugation, the supernatant was filtered using filter paper. Filtrate was collected in a beaker. Diethyl ether (equal volume of filtrate) was added and incubated for $10 \mathrm{~min}$. Then extracts were evaporated until complete dry. And the dried sample was then reconstituted in 2 $\mathrm{ml}$ of methanol and acetone (1:1) and kept for 20 min to reach the solution upto the mark. Finally, TLC plate was dried for $5 \mathrm{~min}$ and observed under UV light chamber to detect the antibiotic residues in meat samples. 


\subsection{Data analysis}

Descriptive analysis was performed. Data were collected and calculated to determine antibiotic resistance and the occurrence of antibiotic residues in poultry, cattle, buffalo and goat meats.

\section{Results}

\subsection{Identification of bacterial agents}

Among 205 meat samples, 77 (37.5\%) were found to be positive for Staphylococcusspp.,48 (22.12\%) were positive for Streptococcus spp.,19 (8.76\%) were positive for Salmonella spp. and 61(29.76\%) were positive for Escherichia coli (E. coli) (Figure 1).

\subsection{Antibiotic resistance pattern of the bacterial agents}

The antibiogram study revealed that the isolated Staphylococcus spp. were highly resistant to cefradine followed by amoxicillin, penicillin, chloramphenicol, erythromycin. The isolates of Streptococcus spp. were highly resistant to amoxicillin followed by cefradine, oxytetracycline, enrofloxacin, penicillin, erythromycin, cotrimoxazole. Isolated E. coli showed varying degrees of sensitivity to antibiotics used in this study with highest sensitivity to cefradine followed by amoxicillin and penicillin. Isolated Salmonella spp. showed highly resistance to cefradine, followed by penicillin and oxytetracycline (Table 2).

\subsection{Antibiotic residues in meats}

The overall prevalence of antibiotic residues in meats was $18.5 \%$ (38/205). In Barishal, prevalence of antibiotic residues in chicken, cattle, buffalo and goat meat was 37.5(15/40), $20.0(6 / 30), 0.0(0 / 5)$ and 10.0\% (1/10), respectively (Figure 2A). In Pirojpur, the prevalence of antibiotic residues in chicken, cattle, buffalo and goat meat was $40.0(6 / 15), 13.3(2 / 15), 0.0(0 / 10)$ and $0.0 \%(0 / 7)$, respectively (Figure $2 \mathrm{~B})$. In Bhola, the prevalence of antibiotic residues in chicken, cattle, buffalo and goat meat was 20.0(3/15), $6.7(1 / 15), 8.6(3 / 35)$ and 12.5\% (1/8), respectively (Figure 2C).

Table 1. Antibacterial agents used for the investigation of antibiotic sensitivity pattern.

\begin{tabular}{|c|c|c|c|c|}
\hline \multirow[t]{2}{*}{ Antibacterial agents } & \multirow[t]{2}{*}{ Concentration $(\mu \mathrm{g} / \mathrm{disc})$} & \multicolumn{3}{|c|}{$\begin{array}{l}\text { Interpretation of results } \\
\text { (Zone diameter in } \mathbf{m m} \text { ) }\end{array}$} \\
\hline & & Resistant & Intermediate & Sensitive \\
\hline Amoxicillin & $10 \mu \mathrm{g}$ & $\leq 11$ & $12-14$ & $\geq 15$ \\
\hline Cefradine & $30 \mu \mathrm{g}$ & $\leq 12$ & $13-15$ & $\geq 16$ \\
\hline Chloramphenicol & $10 \mu \mathrm{g}$ & $\leq 12$ & $13-17$ & $\geq 18$ \\
\hline Ciprofloxacin & $5 \mu \mathrm{g}$ & $\leq 15$ & $16-20$ & $\geq 21$ \\
\hline Colistin sulphate & $10 \mu \mathrm{g}$ & $\leq 8$ & $9-11$ & $\geq 12$ \\
\hline Gentamicin & $10 \mu \mathrm{g}$ & $\leq 12$ & $13-14$ & $\geq 15$ \\
\hline Oxytetracycline & $25 \mu \mathrm{g}$ & $\leq 15$ & $16-25$ & $\geq 26$ \\
\hline Penicillin & $10 \mu \mathrm{g}$ & $\leq 11$ & $12-14$ & $\geq 15$ \\
\hline Tetracycline & $30 \mu \mathrm{g}$ & $\leq 14$ & $15-18$ & $\geq 19$ \\
\hline Vancomycin & $30 \mu \mathrm{g}$ & $\leq 14$ & $15-16$ & $\geq 17$ \\
\hline Enrofloxacin & $15 \mu \mathrm{g}$ & $\leq 10$ & $11-12$ & $\geq 13$ \\
\hline Erythromycin & $15 \mu \mathrm{g}$ & $\leq 13$ & $14-15$ & $\geq 16$ \\
\hline Norfloxacin & $15 \mu \mathrm{g}$ & $\leq 15$ & $16-17$ & $\geq 18$ \\
\hline Cotrimoxazole & $25 \mu \mathrm{g}$ & $\leq 14$ & $15-16$ & $\geq 17$ \\
\hline Azithromycin & $30 \mu \mathrm{g}$ & $\leq 17$ & $18-19$ & $\geq 20$ \\
\hline Tobramycin & $10 \mu \mathrm{g}$ & $\leq 15$ & $16-17$ & $\geq 18$ \\
\hline
\end{tabular}

$\mu \mathrm{g}=$ microgram, $\mathrm{mm}=$ millimeter, $\mathrm{R}=$ resistant, $\mathrm{I}=$ intermediately sensitive, $\mathrm{S}=$ sensitive 
Asian Australas. J. Food Saf. Secur. 2021, 5 (1)

Table 2. Antibiotic resistance patterns of the isolated bacteria.

\begin{tabular}{|c|c|c|c|c|c|}
\hline Antibiotics & & Streptococcus spp. & Staphylococcus spp. & E. coli & Salmonella spp. \\
\hline \multirow[t]{3}{*}{ Vancomycin } & $\mathrm{S}$ & 1 & 2 & 1 & 1 \\
\hline & I & 12 & 11 & 7 & 6 \\
\hline & $\mathrm{R}$ & 11 & 4 & 2 & 5 \\
\hline \multirow[t]{3}{*}{ Tobramycin } & $\mathrm{S}$ & 17 & 10 & 10 & 11 \\
\hline & I & 2 & 1 & 4 & 3 \\
\hline & $\mathrm{R}$ & 0 & 2 & 3 & 4 \\
\hline \multirow[t]{3}{*}{ Erythromycin } & $\mathrm{S}$ & 0 & 0 & 0 & 0 \\
\hline & I & 9 & 4 & 6 & 6 \\
\hline & $\mathrm{R}$ & 15 & 13 & 14 & 16 \\
\hline \multirow[t]{3}{*}{ Azithromycin } & $\mathrm{S}$ & 7 & 3 & 3 & 5 \\
\hline & $\mathrm{I}$ & 13 & 8 & 19 & 15 \\
\hline & $\mathrm{R}$ & 3 & 2 & 4 & 3 \\
\hline \multirow[t]{3}{*}{ Ciprofloxacin } & $\mathrm{S}$ & 11 & 6 & 9 & 7 \\
\hline & $\mathrm{I}$ & 13 & 7 & 12 & 14 \\
\hline & $\mathrm{R}$ & 0 & 0 & 2 & 0 \\
\hline \multirow[t]{3}{*}{ Oxytetracycline } & $\mathrm{S}$ & 0 & 0 & 0 & 0 \\
\hline & I & 5 & 6 & 1 & 2 \\
\hline & $\mathrm{R}$ & 8 & 4 & 8 & 9 \\
\hline \multirow[t]{3}{*}{ Cotrimoxazole } & $\mathrm{S}$ & 5 & 1 & 1 & 2 \\
\hline & $\mathrm{I}$ & 8 & 2 & 4 & 4 \\
\hline & $\mathrm{R}$ & 9 & 4 & 6 & 5 \\
\hline \multirow[t]{3}{*}{ Chloramphenicol } & $\mathrm{S}$ & 11 & 6 & 4 & 3 \\
\hline & I & 6 & 4 & 3 & 3 \\
\hline & $\mathrm{R}$ & 0 & 0 & 0 & 0 \\
\hline \multirow[t]{3}{*}{ Amoxicillin } & $\mathrm{S}$ & 0 & 0 & 0 & 0 \\
\hline & $\mathrm{I}$ & 2 & 1 & 1 & 0 \\
\hline & $\mathrm{R}$ & 19 & 7 & 13 & 8 \\
\hline \multirow[t]{3}{*}{ Colistin } & $\mathrm{S}$ & 3 & 3 & 9 & 3 \\
\hline & $\mathrm{I}$ & 11 & 8 & 18 & 10 \\
\hline & $\mathrm{R}$ & 0 & 0 & 2 & 1 \\
\hline \multirow[t]{3}{*}{ Penicillin } & $\mathrm{S}$ & 1 & 0 & 0 & 0 \\
\hline & $\mathrm{I}$ & 14 & 6 & 1 & 1 \\
\hline & $\mathrm{R}$ & 13 & 12 & 9 & 11 \\
\hline \multirow[t]{3}{*}{ Gentamicin } & $\mathrm{S}$ & 51 & 12 & 10 & 8 \\
\hline & $\mathrm{I}$ & 1 & 0 & 0 & 1 \\
\hline & $\mathrm{R}$ & 0 & 0 & 0 & 0 \\
\hline \multirow[t]{3}{*}{ Cefradine } & $\mathrm{S}$ & 0 & 0 & 0 & 0 \\
\hline & I & 2 & 0 & 0 & 0 \\
\hline & $\mathrm{R}$ & 14 & 9 & 14 & 11 \\
\hline \multirow[t]{3}{*}{ Enrofloxacin } & $\mathrm{S}$ & 0 & 0 & 0 & 0 \\
\hline & $\mathrm{I}$ & 15 & 7 & 11 & 8 \\
\hline & $\mathrm{R}$ & 4 & 2 & 2 & 1 \\
\hline \multirow[t]{3}{*}{ Norfloxacin } & $\mathrm{S}$ & 5 & 3 & 3 & 2 \\
\hline & I & 19 & 13 & 6 & 5 \\
\hline & $\mathrm{R}$ & 2 & 2 & 1 & 2 \\
\hline \multirow[t]{3}{*}{ Tetracycline } & $\mathrm{S}$ & 4 & 5 & 1 & 0 \\
\hline & $\mathrm{I}$ & 9 & 4 & 1 & 1 \\
\hline & $\mathrm{R}$ & 4 & 3 & 2 & 1 \\
\hline
\end{tabular}




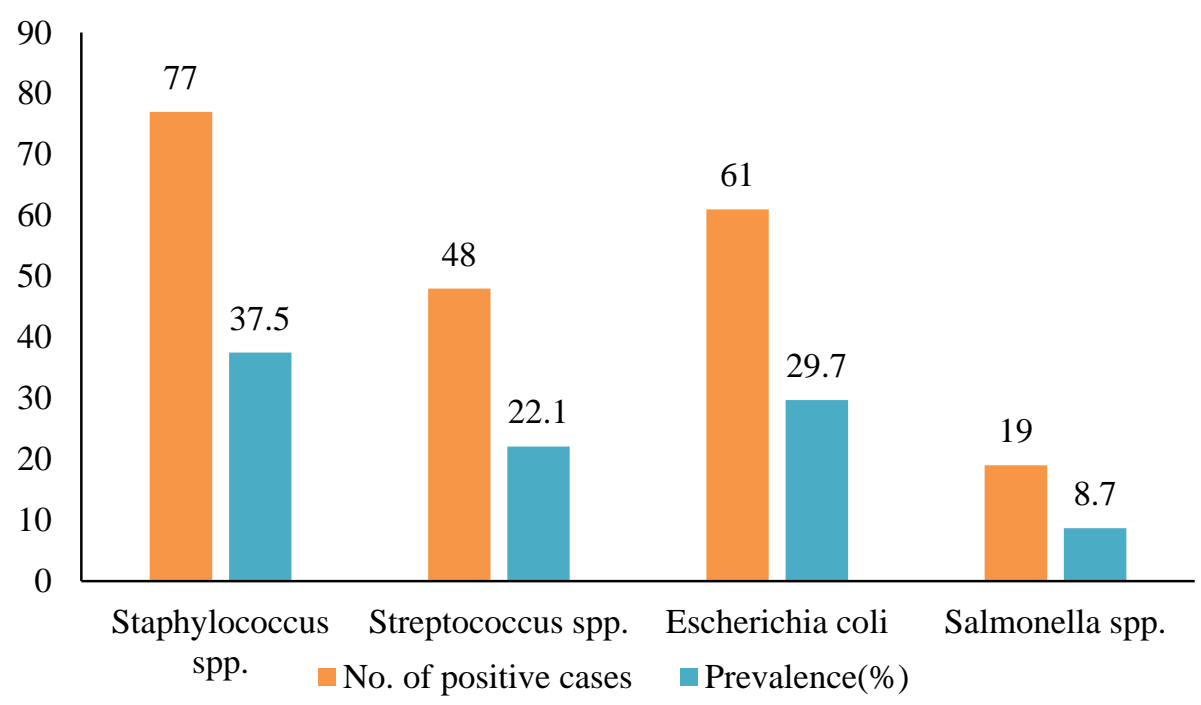

Figure 1. Prevalence of bacterial agents from meat samples.

A

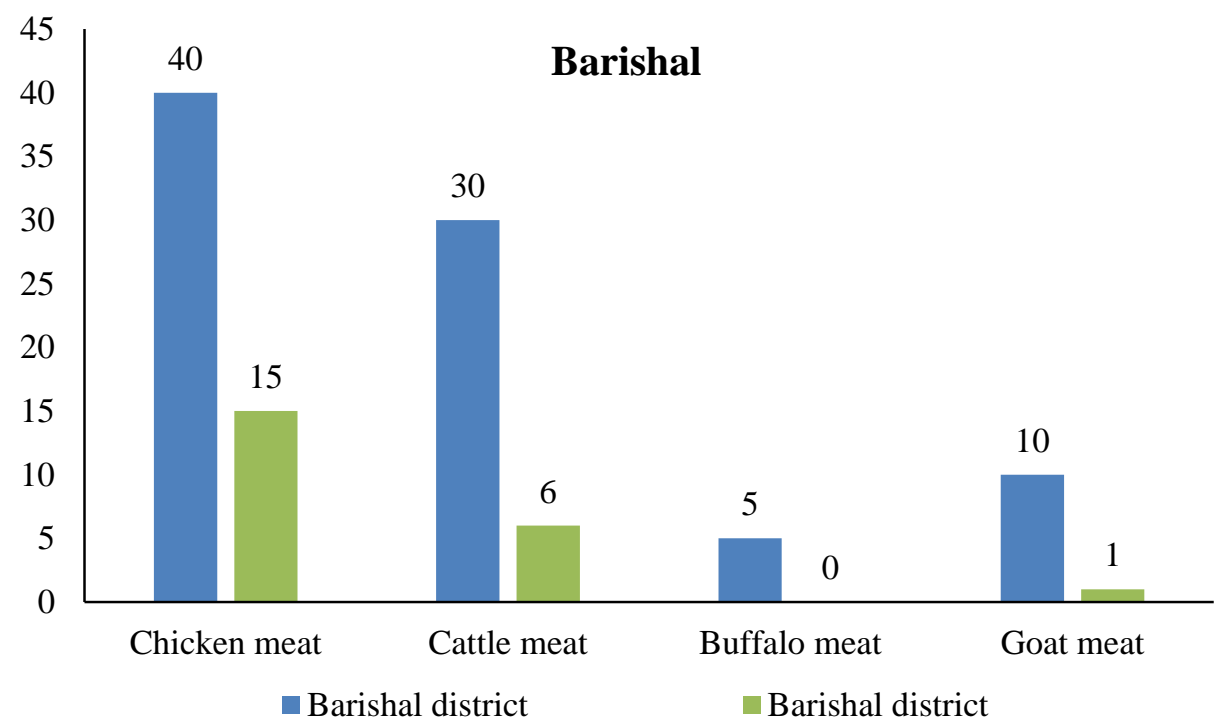

B

\section{Pirojpur}

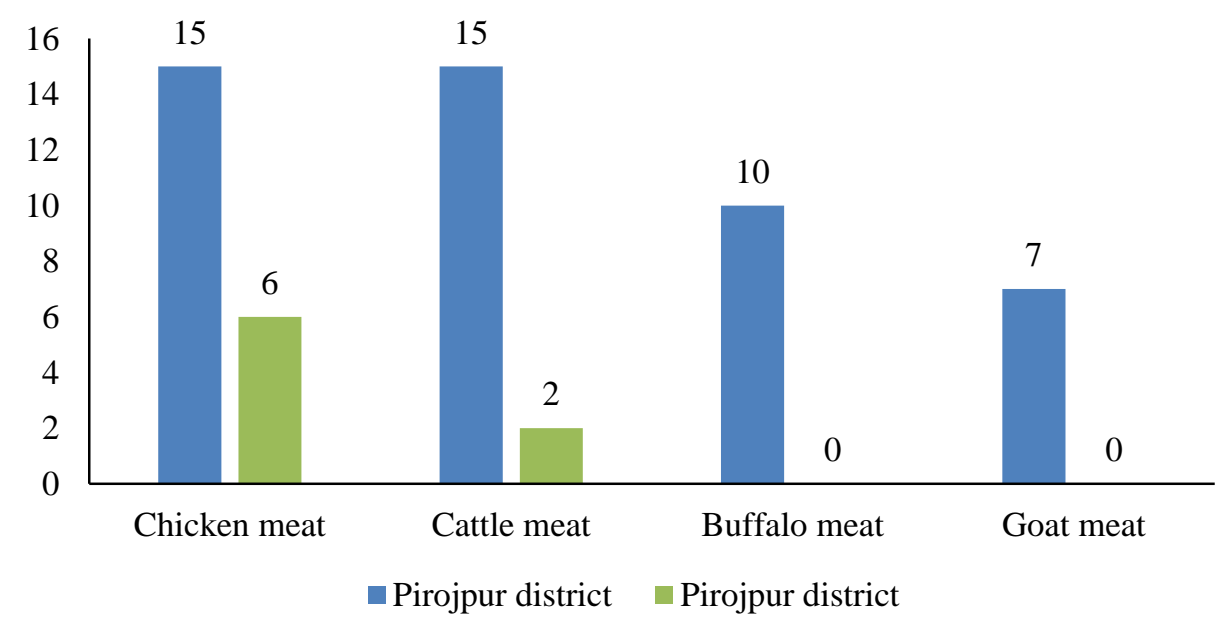


$\mathrm{C}$

Bhola

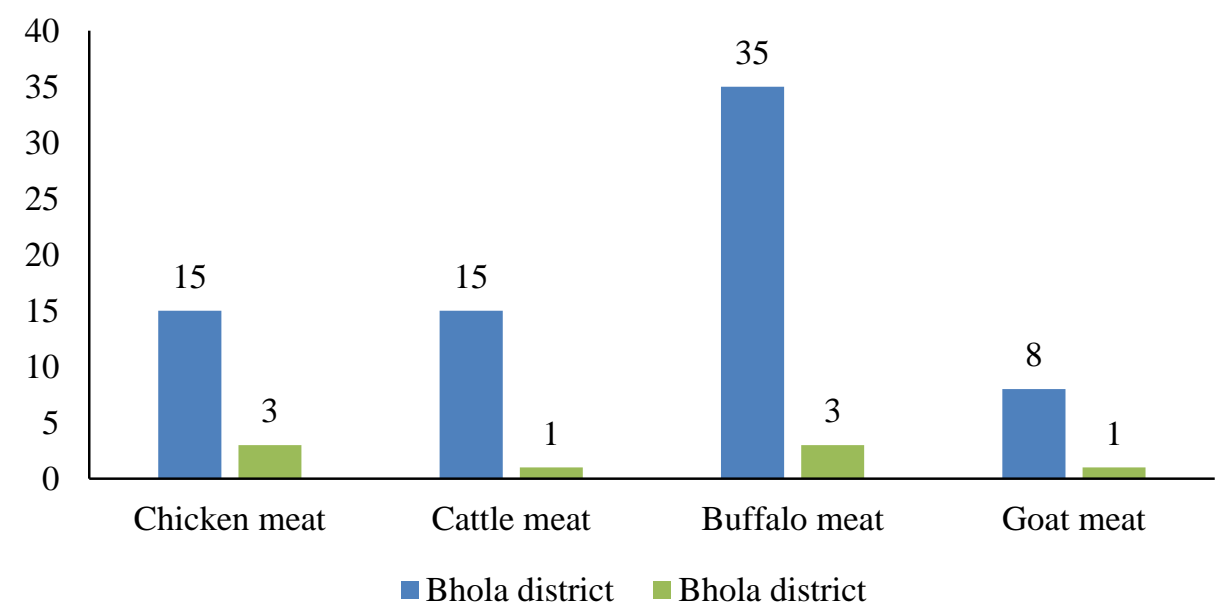

Figure 2. Detection of antibiotic residues in meats by using TLC in Barishal district (A), Pirojpur district (B), and Bhola district (C).

\section{Discussion}

In this study we determined the antibiotic resistance of the isolates obtained from chicken, cattle, buffalo and goat meat collected from different southern districts of Bangladesh. Also, we determined the prevalence of antibiotic residues in these meat samples. We observed that Staphylococcus isolates were highly resistant to amoxicillin, penicillin, chloramphenicol, erythromycin and cefradine. A recent study (Jahan et al., 2015) found that Staphylococcus spp. were highly resistant to amoxicillin, penicillin, and erythromycin. The Streptococcus isolates were highly resistant to amoxicillin and oxytetracycline, followed by erythromycin, penicillin, and cotrimoxazole. A recent study (Cherazard et al., 2017) showed that Streptococcus spp. were resistant to erythromycin and clindamycin. In our study we observed that $E$. coli showed varying degrees of sensitivity to different antibiotics and $E$. coli showed highly resistance to cefradine, followed by amoxicillin and penicillin, which is close to a recent study (Bhuvan et al., 2019). In this study, isolated Salmonella spp. were highly resistant to amoxicillin and cefradine, followed by penicillin, erythromycin, and oxytetracycline. A study by Rahman et al. (2018) also observed that Salmonella spp. isolated from chicken meat were resistant to erythromycin, doxycycline, sulphonamide-trimethoprim, azithromycin, and oxytetracycline. In this study, we observed that the overall prevalence of antibiotic residues in meat was $18.5 \%$. A previous study (Khan et al., 2013) observed $21 \%$ overall prevalence of antibiotic residues in meat and another recent study (Rabin et al., 2017) found $22.0 \%$ overall prevalence of antibiotic residues in meat. In Barishal, the prevalence of antibiotic residues in chicken meat was found $37.5 \%$, which matched the findings of a previous study (Gebre et al., 2012). In Pirojpur, the prevalence of antibiotic residues in chicken meat was found $40.0 \%$, which was close to the findings of a previous report (Sarker et al., 2018). In Bhola, the prevalence of antibiotic residues in chicken meat was $20.0 \%$. Ramatla et al. (2017) observed $24.6 \%$ prevalence of antibiotic residues in chicken meat. In cattle meat, the prevalence of antibiotic residues in Barishal was $20.0 \%$, which was almost similar to the findings of a previous study (Babapour et al., 2012). The prevalence of antibiotic residues in Pirojpur was $13.3 \%$, which supports the findings of a previous study (Sattar et al., 2014). In our study the prevalence of antibiotic residues in Bhola was found 6.7\%, whereas Nhung et al. (2018) reported $9.5 \%$ prevalence of antibiotic residues in cattle meat. In buffalo meat, the prevalence of antibiotic residues in Bhola was found $8.6 \%$, but no antibiotic residue was found in buffalo meats of Barishal and Pirojpur district. A previous study (Khan et al., 2013) reported $23.3 \%$ prevalence of antibiotic residues in buffalo meat. The prevalence of antibiotic residues in goat meat of Barishal and Bhola district was 10.0 and $12.5 \%$, respectively. No antibiotic residue was found in goat meat of Pirojpur district. A previous study (Hossain et al., 2011) reported $15.3 \%$ prevalence of antibiotic residues in goat meat.

\section{Conclusions}

In conclusion, the isolates obtained from the meat samples in this study showed varied degrees of sensitivity and resistance patterns toward different antibacterial agents. Antibiotic residues were relatively higher in poultry meat than that of other meat types in different southern districts of Bangladesh, which indicates more frequent 
use of antibiotics in chicken meat production and is a potential threat to human health. The findings of the study will help to increase the awareness among the people regarding the use of antibiotics for healthy meat production.

\section{Acknowledgements}

This study was funded by the Bangladesh Agricultural Research Council (Project id: PSTU-138, PIU-BARC, NATP-2). We acknowledge the laboratory support from Chattogram Veterinary and Animal Sciences University (CVASU), Bangladesh.

\section{Conflict of interest}

None to declare.

\section{References}

Babapour A, I Azami and J Fartashmehr, 2012. Overview of antibiotic residues in beef and mutton in Ardebil, North West of Iran. World Appl. Sci. J., 19: 1417-1422.

Bauer AW and WM Kirby, 1966. Antibiotic susceptibility testing by standards single disc method. Am. J. Clin. Pathol., 45: 493-496.

Bhuvan S, P Govinda, S Khichaju, D Bajracharya, G Dhungana and V Shrestha, 2019. Multidrug-resistant bacteria from raw meat of buffalo and chicken, Nepal. Vet. Med. Int., 2019: 7960268.

Casewell M, C Friis, E Marco, P McMullin and I Phillips, 2003. The European ban on growth-promoting antibiotics and emerging consequences for human and animal health. J. Antimicrob. Chemother., 52: 159161.

Chanda R, R Fincham and P Venter, 2014. Review of the regulation of veterinary drugs and residues in South Africa. Crit. Rev. Food Sci. Nutr., 54: 488-494.

Cheesbrough M, 1984. Medical Laboratory Manual for Tropical Countries. v. II: Microbiology, Cambridgeshire, Tropical Health Technology. https://doi.org/10.1590/S0036-46651985000400013

Cherazard R, M Epstein, TL Doan, T Salim, S Bharti and MA Smith, 2017. Antimicrobial resistant Streptococcus pneumoniae: prevalence, mechanisms, and clinical implications. Am. J. Ther., 24: 361-369.

Doyle ME, 2006. Veterinary drug residues in processed meats-potential health risk. Food research institute university of Wisconsin-Madison, FRI briefings., 51: 148-196.

Gebre BA, 2012. Qualitative screening of antibiotic residues and identification of antibiotic resistant salmonella from raw and ready to eat meat in Thailand. Int. J. Adv. Lif. Sci., 5: 51-64.

Jahan M, M Rahman, MS Parvej, SM Chowdhury, Z Haq, ME Haque, MAK Talukder and S Ahmed, 2015. Isolation and characterization of $S$. aureus from raw cow milk in Bangladesh. J. Adv. Vet. Anim. Res., 2: $49-55$.

Jinap S, CK Cheong, P Haje and MR Ismail-Fitry, 2010. Sulfonamides determination in chicken meat products from Malaysia. Int. Food Res. J., 17: 885-892.

Khan K, A Rahman, MS Quresshi, U Sadique, J Ali, N Ahmad and M Ahmad, 2013. Drug residues in cattle and buffalo meat in Peshawar, Pakistan. International Workshop on Dairy Science Park 2013.

Lee HJ, MH Lee and PD Ruy, 2001. Public health risks: chemical and antibiotic residues. Asian-Australas J. Anim. Sci., 14: 402-413.

Long AR, LC Hsieh, MS Malbrough, CR Short and SA Barker, 1990. Multiresidue method for the determination of sulfonamides in pork tissue. J. Agric. Food Chem., 38: 423-426.

Mathew AG, MA Beckmann and AM Saxton, 2001. A comparison of antibiotic resistance in bacteria isolated from swine herds in which antibiotics were used or excluded. J. Swine Health Prod., 9: 125-129.

Michael GB, H Kaspar, AK Siqueira, EF Costa, LG Corbellini, K Kadlec and S Schwarz, 2017. Extended spectrum $\beta$-lactamase (ESBL) producing Escherichia coli isolates collected from diseased food producing animals in the GERM-Vet monitoring program 2008-2014. Vet. Microbiol., 200: 142-150.

Nhung NT, NTB Van, NV Cuong, TTQ Duong, TT Nhat, TTT Hang, NTH Nhi, BT Kiet, VB Hien, PT Ngoc, J Campbell, G Thwaites and J Carrique-Mas, 2018. Antimicrobial residues and resistance against critically important antimicrobials in non-typhoidal Salmonella from meat sold at wet markets and supermarkets in Vietnam. Int. J. Food Microbiol., 266: 301-309.

Packer RA and IA Merchant, 1967. Veterinary Bacteriology and Virology. 7th Ed, The Iowa University Press, Ames, Iowa, USA, pp: 286-306.

Poppelka P, J Nagy, R Germuska, KS Marcinca, P Jevinova and A Derijk, 2005. Comparison of various assays used for detection of beta-lactam antibiotics in poultry meat. Food Addit. Contam., 22: 557-562. 
Rabin R, RK Mandal, K Kaphle, D Pant, S Nepali and A Shrestha, 2017. Assessment of antibiotic residues in the marketed met of Kailali and Kavre of Nepal. Int. J. App. Sci. Biotechnol., 5: 386-389.

Rahman MA, AKM Rahman, MA Islam and MM Alam, 2018. Detection of multi-drug resistant Salmonella from milk and meat in Bangladesh. Bangladesh J. Vet. Med., 16: 115-120.

Ramatla T, L Ngoma, M Adetunji and M Mwanza, 2017. Evaluation of antibiotic residues in raw meat using different analytical methods. J. Antibiot. 6: 1-17.

Sarker YA, MM Hasan, TK Paul, SZ Rashid, MN Alam and MH Sikder, 2018. Screening of antibiotic residues in chicken meat in Bangladesh by thin layer chromatography. J. Adv. Vet. Anim. Res., 5: 140-145.

Sattar S, MM Hassan, SKMA Islam, M Alam, MSA Faruk, S Chowdhury and AKM Saifuddin, 2014. Antibiotic residues in broiler and layer meat in Chittagong district of Bangladesh. Vet. World, 7: 738-743.

Wadoum REG, NF Zambou, FF Anyangwe, JR Njimou, MM Coman, MC Verdenelli, C Cecchini, S Silvi, C Orpianesi, A Cresci and V Colizzi, 2016. Abusive use of antibiotics in poultry farming in Cameroon and the public health implications. Br. Poult. Sci., 57: 483-493.

Walton J, 1988. Antibiotic resistance: An Overview. Vet. Rec., 122: 249-251. 